\title{
Phacoemulsification with PMMA IOL Vs Phacoemulsification with Foldable ACRYLIC IOL .A Comparative Study
}

\author{
Dr Rajendra Prasad $\mathbf{J}^{1}$, Dr Lakshmi Saroja $\mathrm{P}^{2}$. \\ ${ }^{1}$ Associate Professor, Dept of Ophthalmology, Dr PSIMS \& RF, Chinoutpally \\ ${ }^{2}$ Resident, Dept of Ophthalmology, Dr PSIMS\&RF, Chinoutpally
}

\begin{abstract}
Aim of the study: To compare the visual outcome in patients underwent cataract surgery with PMMA IOL and Foldable Acrylic IOL in Phacoemulsification

Materials \& Methods: Ours is a prospective study including 100 patients who underwent cataract surgery in Dr PSIMS hospital .The total patients divided into two groups. Each group comprising of 50 patients. All the patients underwent phacoemulsification for cataract. The first half were given PMMA IOL and the second half were given Foldable Acrylic IOL.

Results: Out of 50 patients who had PMMA IOL,40 patients got BCVA of 6/6 post operatively at the end of six weeks. Three had 6/9.Another three got BCVA of 6/12.In three patients the BCVA is 6/18. Five cases had PCR. Among another 50 patients who were given Foldable Acrylic IOL, 42 had BCVA of 6/6. Five patients had 6/9, and three had 6/18. Five patients had PCR. The average post operative astigmatism was $0.625 D$.

Discussion: The post operative refraction was stabilised at the end of 4 weeks in both the groups. All the eyes had less than $0.75 D$ of astigmatism at the end of six weeks post operatively.

Conclusion: The visual outcome in phacoemulsification with PMMA IOL and Acrylic foldable IOL has less significance in terms of the type of IOL.
\end{abstract}

Keywords: phacoemulsification, IOL [Intra Ocular Lens], Astigmatism, BCVA[Best Corrected Visual Acuity

\section{Introduction}

Blindness as defined by W H O is "visual acuity less than $3 / 60$ (snellen) or its equivalent", ${ }^{1}$ i.e. inability to count fingers in day light at a distance of 3 meters ${ }^{2}$

The concept of avoidable blindness ( i.e. preventable or curable) has gained importance recently, cataract being one of them ${ }^{3}$, Cataract which literally means waterfall ${ }^{4}$ which is defined as any opacity of the lens or its capsule whether developmental or acquired. ${ }^{5}$

Inspite of the availability of a surgical treatment, age related cataract is the leading cause of blindness world wide, accounting for vision loss in more than half of the 23 million persons. Population projections indicate that the world wide prevalence of blindness from cataract could reach close to 40 million by the year 2025.

In India, National survey on blindness from 2001-2002 shows prevalence of blindness in general population to about $1,1 \%$. The principal cause of which is cataract, responsible for about $62.6 \%$ in all cases ${ }^{6}$. In India 3.8 million persons become blind from cataract each year .The National programme for control of blindness (NPCB) was launched in 1976 with emphasis on gradual shift from camp surgeries to institutional surgeries with importance given to the quality of cataract surgery in relation to equipment and training to all level of medical personnels ${ }^{7,8}$.

On Feb $18^{\text {th }} 1999$ initiative was launched by WHO known as Vision 2020: The right to sight, The objective of which is to eliminate the avoidance of blindness by $2020.1 \mathrm{t}$ also states that cataract surgical services should be provided that have a high success rate in terms of visual outcome and improved quality of life, ${ }^{9}$.

\section{Aims and Objectives}

1. To compare the post operative visual faculties in both types of surgeries,

2. To study the post operative changes in conical curvature and astigmatism levels,

3. To study incidence of any complication associated with both types of surgery with intra ocular lenses.

III. Materials And Methods

A prospective study of 100 patients includes 50 cases with PMMA and 50 cases with foldable ACRYLIC IOLS. 
All the patients included in this study had nuclear cataracts with or without posterior sub capsular component,

The Preoperative assessment included the following parameters

1. Detailed slit lamp examination of anterior segment,

2. Detailed fundus examination,

3. Snellens visual acuity unaided and with pin hole.

4. Intra ocular pressure with schiotz tonometer.

5. Naso lacrimal patency.

6. Keratometry by Bausch and lombkeratometer.

7. A scan biometry.

8. IOL power calculation using SRK - 1 formula.

9. Pupillary dilatation.

All patients were given peribulbar anaesthesia with $6 \mathrm{ml}$ of 1: 1 mixture of $2 \%$ lignocaine and $0.5 \%$ bupivacaine, hyaluronidase , 12,5 I.U/ml of adrenaline 1 in 1 lakh. Incision given in my study is superotemporal scleral incision.

\subsection{Inclusion Criteria:}

1. Patients with nuclear sclerosis grade 2 with or without posterior sub capsular component

2. With normal infra ocular pressure

3. With patent lacrimal apparatus

4. With normal cornea without dystrophies

\subsection{Exclusion Criteria:}

1. Patient with ocular abnoimalities like glaucoma, uveitis

2. Patients with systemic abnormalities such as diabetes mellitus.

\subsection{Risk Factors:}

There are no risk factors involved in this study,

\subsection{Procedure For Implantation of PMMA IOL :}

The incision was enlarged with a 5.2 keratome and the rigid IOL was implanted,

\subsection{Procedure for Implantation of Foldable Acrylic IOL :}

The pusher is loaded on to injector from the pusher holder, inner surface of cartridge is lubricated with a visco elastic, the lens is pushed down with a forceps. Between the bends of it sits properly in the slot. The piston is advanced firmly till it enters smoothly in to the wings and the wings are parallel closed, The cartridge wings are held together tightly to keep the loaded cartridge closed. The cartridge is slid in to the opening of injector till cartridge, The tip is inserted through the incision, The lens is injected with in minute or two and it is important to make sure that the haptics are not caught between the wings when they are closed. The IOL is dailed smoothly in to the bag and the visco elastic is thoroughly aspirated, and the conjunctival flap is cauterized, Subconjunctival decadran and gentamycin are given, Pad and bandage applied.

Postoperative assessment was done on $1^{\text {st }}$ post operative day and patient was discharged from the hospital, Further postoperative assessment was done at the end of $1^{\text {st }}$ week, $2^{\text {nd }}$ week, $4^{\text {th }}$ week and $6^{\text {th }}$ week,

The post operative assessment included the following parameters

1. Slit lamp examination of anterior segment

2. Snellens visual acuity unaided and with pin hole

3. fondus examination

4. Keratometry by Bausch and lomb keratometer at the end of $4^{\text {th }}$ week and $6^{\text {th }}$ week,

5. Best corrected visual acuity at the end of $4^{\text {th }}$ week and $6^{\text {th }}$ week,

6. Surgically induced Astigmatism was calculated using Vector analysis,

\section{Observations And Results}

Our study was a prospective randomized study consisting of 50 eyes for phacoemulsification with PMMA intraocular lens and 50 eyes for phacoemulsification with Acrylic intraocular lens in the Department of Ophthalmology, PSIMS, Gannavaram between 2013-2014. 


\section{PMMA Group Observations:}

In 50 eyes who underwent phacoemulsification with PMMA lenses, 26 were male and 24 were female. 5 patients out of 50 were less than 50 years, 19 patients were between 51-60, 22 between $61-70,3$ between 71 80 and 1 was above 81 years,

The pre-op vision in the PMMA group was 2/60-3/60 in 23 patients , 4/60-5/60 in 18 patients and 6/606/36 in 9 patients. On Refraction 37 patients showed improvement in vision and 13 patients showed nuclear cataract with dense PSCC, which had no improvement of vision. Of these 13 patients 4 had 2/60, 5 had 3/60 and 4 had 4/60.

Table 6: pre op vision in PMMA group

\begin{tabular}{|c|c|c|}
\hline Pre-op Vision & Unaided Eyes & Refraction \\
\hline $2 / 60-3 / 60$ & 23 & Not possible \\
\hline $4 / 60-5 / 60$ & 18 & Not possible \\
\hline $6 / 60-6 / 36$ & 9 & 19 \\
\hline $6 / 24-6 / 18$ & 0 & 18 \\
\hline No improvement & & 13 \\
\hline
\end{tabular}

Table 7: Pre-op Keratometry in PMMA Group

\begin{tabular}{|c|c|c|}
\hline Pre-op Keratometry & $\mathbf{K}_{\mathbf{I}}$ & $\mathbf{K}_{\mathbf{2}}$ \\
\hline 40-42D & 4 & 5 \\
\hline 42-44D & 25 & 18 \\
\hline 44-46D & 17 & 23 \\
\hline $46-48 \mathrm{D}$ & 4 & 4 \\
\hline
\end{tabular}

Table 8 : Post op vision in PMMA Group after 4 weeks

\begin{tabular}{|c|c|}
\hline Post op Vision & No of Eyes \\
\hline $6 / 6$ & 36 \\
\hline $6 / 9$ & 9 \\
\hline $6 / 12$ & 3 \\
\hline $6 / 18$ & 2 \\
\hline $6 / 24$ & 0 \\
\hline
\end{tabular}

Table 9 : Post op vision in PMMA Group after 6 weeks

\begin{tabular}{|c|c|}
\hline Post op Vision & No of Eyes \\
\hline $6 / 6$ & 40 \\
\hline $6 / 9$ & 3 \\
\hline $6 / 12$ & 3 \\
\hline $6 / 18$ & 3 \\
\hline $6 / 24$ & 1 \\
\hline
\end{tabular}

Post op Keratometry in the horizontal meridian was around 44-46D in 21 patients, 42-44D in 17 patients. While in the vertical meridian 30 patients had 44-46D and 12 in 42-44D

Table 10 : Post op Keratometry in PMMA Group

\begin{tabular}{|c|c|c|}
\hline Postop Keratometry & $\mathrm{K}_{\mathrm{l}}$ & $\mathrm{K} 2$ \\
\hline $40-42 \mathrm{D}$ & 2 & 2 \\
\hline $42-44 \mathrm{D}$ & 17 & 12 \\
\hline $44-46 \mathrm{D}$ & 21 & 30 \\
\hline $46-48 \mathrm{D}$ & 10 & 6 \\
\hline
\end{tabular}




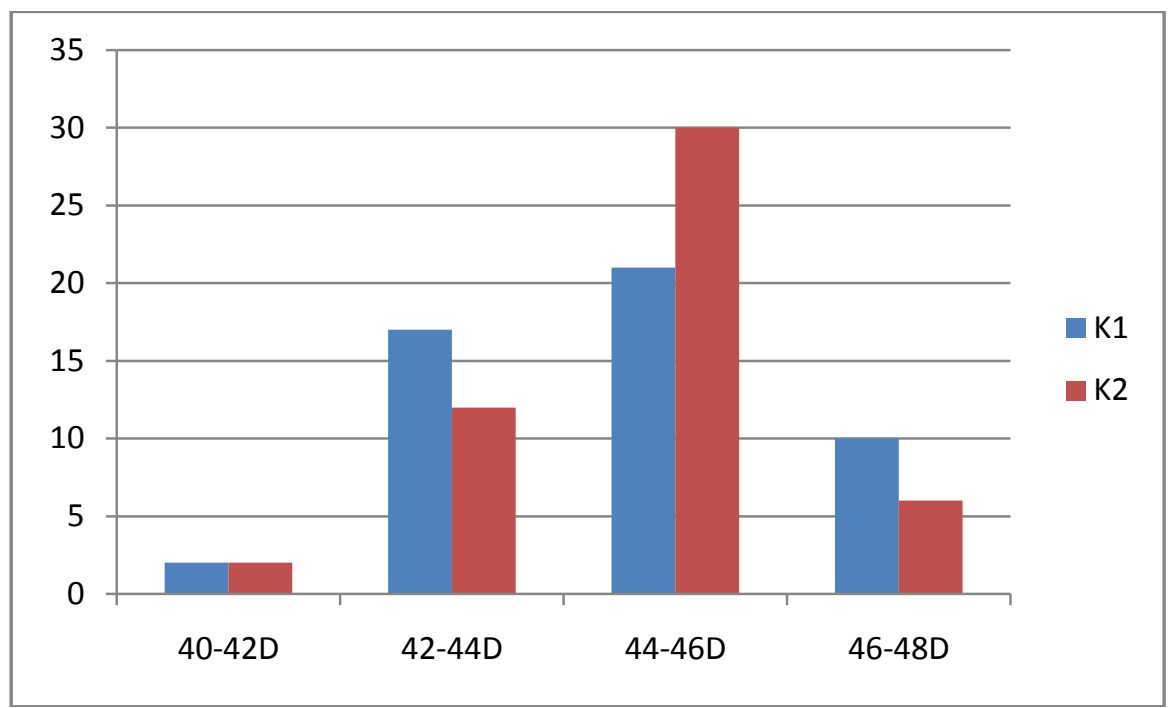

Figure 1: Post op Keratometry in PMMA Group

Table 11: Surgically induced Astigmatism in PMMA Group

\begin{tabular}{|c|c|}
\hline Astigmatism & No of Eves \\
\hline $0.25 \mathrm{D}$ & 4 \\
\hline $0.5 \mathrm{D}$ & 20 \\
\hline $0.75 \mathrm{D}$ & 14 \\
\hline $\mathrm{ID}$ & 7 \\
\hline $1.25 \mathrm{D}$ & 3 \\
\hline $1.5 \mathrm{D}$ & 1 \\
\hline No Change & 1 \\
\hline
\end{tabular}

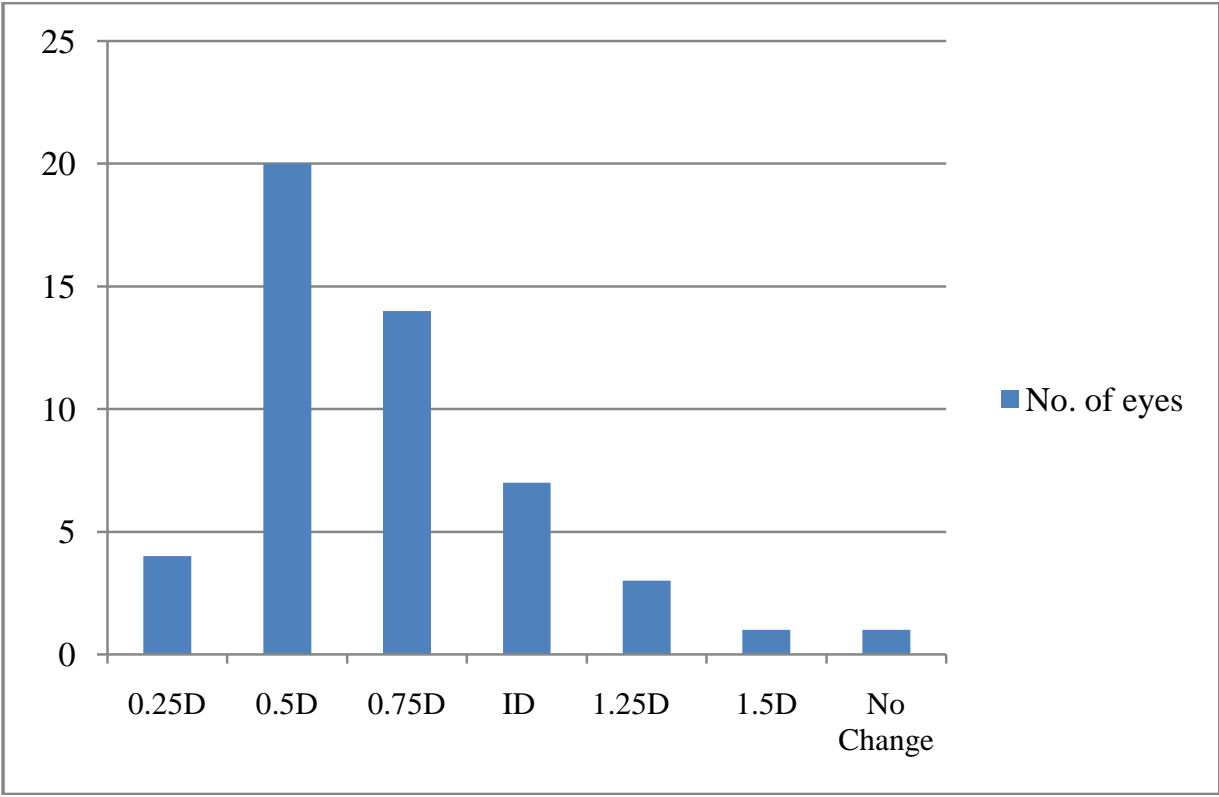

Figure 2 : Surgically induced Astigmatism in PMMA Group

\section{Acrylic Group Observations}

In 50 eyes who underwent phacoem unification with Acrylic lenses, 24 were male and 26 were female, 6 patients out of 50 were less than 50 years, 15 patients were between $51-60,21$ between $61-70,8$ between 71 80 and none above 80 years,

The pre op vision in the Acrylic group was 2/60-3/60 in 17 patients, 4/60-5/60 in 18 patients and 6/60-6/36 in 15 patients. On Refraction 40 patients showed improvement and 10 patients showed no improvement who had dense PSCC. 
Table 12 : Pre-op Vision in Acrylic lens Group

\begin{tabular}{|c|c|c|}
\hline Pre-op Vision & Unaided Eyes & Refraction \\
\hline $2 / 60-3 / 60$ & 17 & Not Possible \\
\hline $4 / 60-5 / 60$ & 18 & Not Possible \\
\hline $6 / 60-6 / 36$ & 15 & 18 \\
\hline $6 / 24-6 / 18$ & 0 & 22 \\
\hline No improvement & & 10 \\
\hline
\end{tabular}

The Pre op keratometry in the Acrylic group, 22 had 42-44D, 18 had 44-46D and 10 had 46-48D in the horizontal meridian, while in the vertical meridian 20 patients had 42-44D, 24 had 44-46D and 6 patients in 4648D.

Table 13 : Pre-op Keratometry in Acrylic lens Group

\begin{tabular}{|c|c|c|}
\hline Pre-op Keratometry & $\mathbf{K}_{\mathbf{l}}$ & $\mathbf{K}_{\mathbf{2}}$ \\
\hline $40-42 \mathrm{D}$ & 0 & 0 \\
\hline $42-44 \mathrm{D}$ & 22 & 20 \\
\hline $44-46 \mathrm{D}$ & 18 & 24 \\
\hline $46-48 \mathrm{D}$ & 10 & 6 \\
\hline
\end{tabular}

The Post op Vision in the Acrylic group was $6 / 6$ in 42 patients, $6 / 9$ in 5 patients and 6/18 in 3 patients.

Table 14: Post op vision in Acrylic lens Group at 4 weeks.

\begin{tabular}{|c|c|}
\hline Post op Vision & No of Eyes \\
\hline $6 / 6$ & 40 \\
\hline $6 / 9$ & 7 \\
\hline $6 / 12$ & 0 \\
\hline $6 / 18$ & 3 \\
\hline $6 / 24$ & 0 \\
\hline
\end{tabular}

Table 15: Post op vision in Acrylic lens Group at 6 weeks.

\begin{tabular}{|c|c|}
\hline Post op Vision & No of Eyes \\
\hline $6 / 6$ & 42 \\
\hline $6 / 9$ & 5 \\
\hline $6 / 12$ & 0 \\
\hline $6 / 18$ & 3 \\
\hline $6 / 24$ & 0 \\
\hline
\end{tabular}

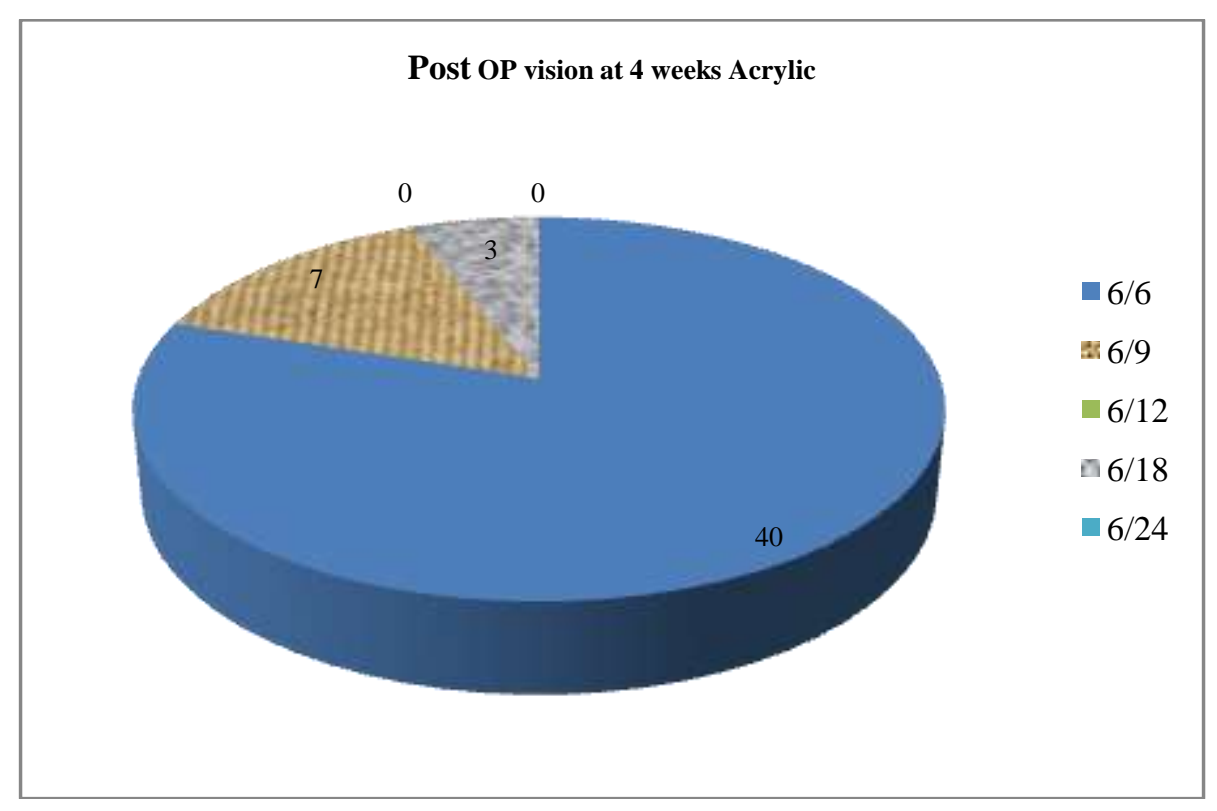

Figure 3 : Post op Vision in Acrylic Group, 


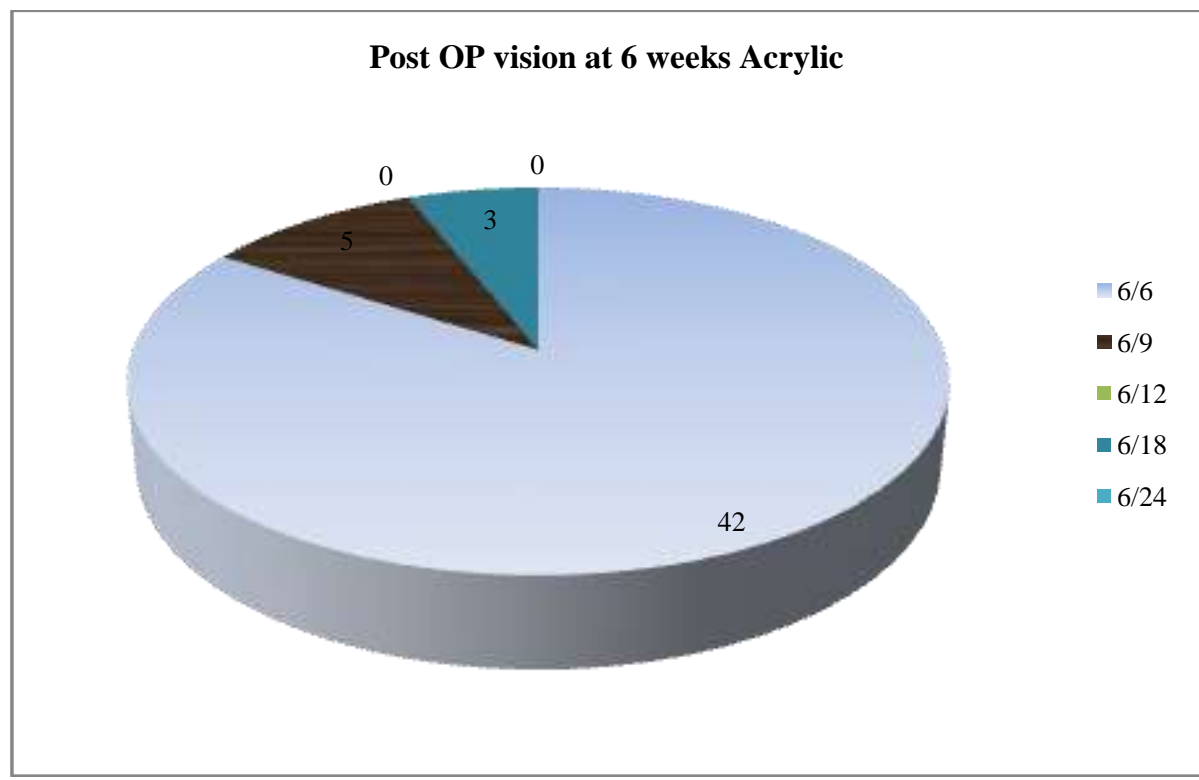

Figure 4 : Post op Vision at 6 weeks

The post op Keratometry in the Acrylic group was 42-44D in 23 patients, 44-46D in 15 patients and 46-48D in 12 patients in the horizontal meridian. In the vertical 20patients had 42-44D, 23patients had 44-46D and 7 patients had $46-48 \mathrm{D}$,

Table 16: Post-op Keratometry in Acrylic lens Group

\begin{tabular}{|c|c|c|}
\hline Post op Keratometry & Kl & K2 \\
\hline $40-42 \mathrm{D}$ & 0 & 0 \\
\hline $42-44 \mathrm{D}$ & 23 & 20 \\
\hline 44-46D & 15 & 23 \\
\hline $46-48 \mathrm{D}$ & 12 & 7 \\
\hline
\end{tabular}

Surgically induced Astigmatism in the acrylic group was $0.25 \mathrm{D}$ in 19 patients, $0.5 \mathrm{D}$ in 19 patients, $0.75 \mathrm{D}$ in 3 patients and no change in astigmatism in 9 patients.

Table 17 : Surgically induced Astigmatism in Acrylic lens group

\begin{tabular}{|c|c|}
\hline Astigmatism & No of Eyes \\
\hline $0.25 \mathrm{D}$ & 19 \\
\hline O.SD & 19 \\
\hline $0.75 \mathrm{D}$ & 3 \\
\hline ID & 0 \\
\hline $1.25 \mathrm{D}$ & 0 \\
\hline $1.5 \mathrm{D}$ & 0 \\
\hline No Change & 9 \\
\hline
\end{tabular}




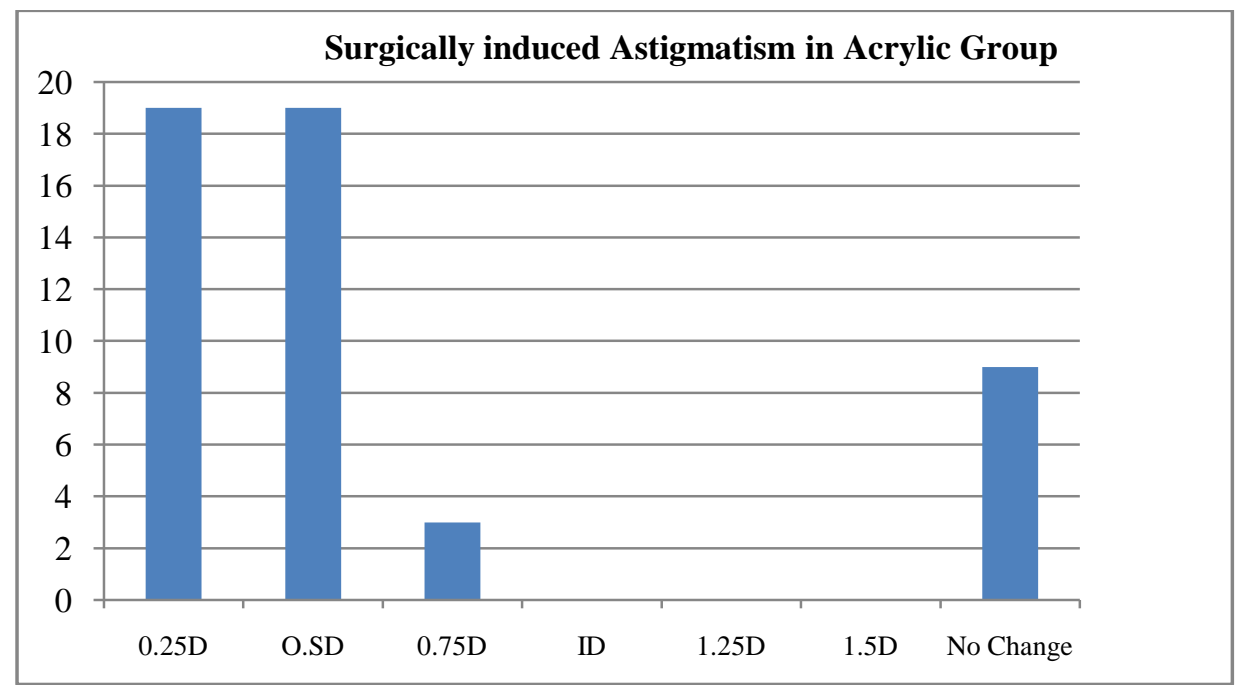

Figure 5 : Surgically induced Astigmatism in Acrylic group.

3 cases developed small posterior capsular rent for which anterior vitrectomy was done and IOL placed in the bags as the hyaloid phase of the vitreous has been disturbed, Cystoidmacular oedema occured, hence after 4 weeks 3 eyes had 6/18 vision.

\section{Discussion}

A prospective randomized study of 100 eyes of 100 patients operated for senile cataracts by phacoemulsification at our institute out of which 50 eyes underwent implantation of foldable acrylic intraocular lenses and 50 eyes underwent implantation of rigid polymethylmethacrylate intraocular lenses.

All patients had senile cataracts without any associated glaucoma or uveitis. All of them were nondiabetic people. All of the eyes had normal anterior segments and normal fundus. All of the eyes had nuclear cataract. In addition to this, some eyes had dense posterior sub capsular cataract. No patient had pre- existing lens abnormalities like phacodonesis, zonulolysis or congenital posterior capsular dehiscence.

All the patients were aged between 43 and 84 years of age. All the patients underwent thorough preoperative assessment and biometry.

In 50 eyes who underwent phacoemulsification with PMMA lenses 26 belonged to male patients and 24 belonged to female patients. Out of these 50 eyes, 40 eyes attained best corrected visual acuity of 6/6, 3 attained 6/9, 3 attained 6/12, another 3 attained 6/18. One patient developed cystoid macular oedema, so vision dropped to $6 / 24$ after one month, Later on with topical NSAID treatment, this patient attained bestcorrected visual acuity of 6/9, 5 cases had posterior capsular rent in which anterior vitrectomy was done and IOL placed in the bag. These 5 patients were given topical NSAID drops along with routine postoperative steroids. These were unrelated to the lens,

In 50 patients who underwent phacoemulsification with implantation of acrylic intraocular lenses 24 were male patients and 26 were female patients. Out of these 50 eyes, 42 eyes attained best corrected visual acuity of 6/6, 5 eyes attained 6/9 and 3 eyes attained 6/18. 5 cases had posterior capsular rent in which anterior vitrectomy was done and IOL placed in the bag. These 4 patients were given topical NSAID drops along with routine postoperative steroids. These were unrelated to the lens.

Based on the preoperative, post operativekeratometry values and post operative final refraction at 6 weeks, the average surgically induced astigmatism in this group was $0,625 \mathrm{D}$, The post operative refraction stabilized by $4^{\text {th }}$ postoperative week in 44 eyes, There was a significant difference between postoperative refraction at $4^{\text {th }}$ and $6^{\text {th }}$ weeks in 6 eyes. All the eyes had less than $0.75 \mathrm{D}$ of surgically induced astigmatism at the end of post-operative 6th week, 3 eyes had post operative iritis which subsided completely with routine postoperative topical steroid eyedrops. No patient required cycloplegia in addition to topical steroids.

There is no statistical difference in both post operativebestcorrected visual acuity after $6^{\text {th }}$ postoperative week and surgically induced astigmatism betweenphacoemulsification with PMMA lenses and phacoemulsification with acrylic lenses in our study.

Another study "Clinical Performance of Akreos Adapt (Bausch Lomb ) IOL, was I done at Raj an eye care hospital, Chennai. This study clearly demonstrates the efficacy of I the newer generation $26 \%$ UV hydrophilic acrylic to prevent PCO formation yielding I excellent results. Good visual outcome was noted in both the PMMA and Hydrogel I groups, and rapid visual recovery in hydrophilic Acrylic group. ${ }^{10}$ 
Aasuri MK, et al conducted a prospective study comparing acrylic and PMMA tocompare the incidence of PCO and post operative uveal inflammation, All the patients

I maintained or improved their vision. They concluded that incidence of PCO and post operative uveal inflammation is significantly less with acrylic lenses and safer to use in paediatric eyes. ${ }^{11}$

Kuchle $\mathrm{M}_{9}$ et al conducted a retrospective study and compared results and complications of hydrophobia acrylic Vs PMMA IOL in paediatric age group. Postoperative visual outcome was comparable in both groups. The rate of PCO necessitating YAG capsulotomy was lower in Acrylic group than in PMMA, but the difference did not reach statistical Significance.

Mahamoud -Reza Panahi- Bazaz et al conducted a randomized clinical trial comparing primary implantation of foldable hydrophilic Acrylic with PMMA IOLs in paediatric cataract. Visual axis remained completely clear and visual outcomes were generally favorable and comparable in study groups. ${ }^{13 .}$

\section{Conclusion}

acuity and surgically induced astigmatism is comparable in both Acrylic and PMMA 1OLs groups with no significant difference. There is no difference in post opcomplications in both types of Intraocular lenses, However the PMMA IOL grouprequired longer time for post operative visual rehabilitation probably related to larger incision for PMMA IOL implantation. But to compare the incidence of posterior capsularopacification the patients are to be followed for a longer duration.

As the visual outcome is comparable in both techniques it may be beneficial to do the surgery by cheaper technique in a developing country like ours.

[1]. WHO. Techn. Rep. Ser., no. 518. 1973.

\section{Bibliography}

[2]. WHO. Epi \& Vital statis report, 19: 437.1996.

[3]. BiettiG.B.World Health, Feb-Mar, 1976.

[4]. Stedman's Concise Medical Dictionary illustrated, $2^{\text {nd }}$ edition, philadelphia. Williams \& Wilkins. 1994.

[5]. Revised by Sihota R, Tandon R, Parson's Disease of the Eye, $21^{\text {st }}$ Edition, New Delhi, Butterworth-Heinmann. Chapter 18.pg 257 pg 257.

[6]. Govt of India. Health Information of India. DGHS, NewDelhi, 1986.

[7]. WHO Guidelines for programmes for the prevention of Blindness, Geneva, 1979.

[8]. WHO 2000, Strategic plan for vision 2020: The right to Sight, illumination of avoidable blindness in South East Region, New Delhi.

[9]. Myron Yanoff \& Jay S Duker, $3^{\text {rd }}$ Edition. pg 426.

[10]. Clinical Performance of Akreos Adapt (Bausch \& Lomb) IOLO, Dr. B. Praveen, DO, Dr. Priya, DO, DNB, Dr.Sujatha Mohan, DO, Dr. Mohan Rajan, DO,DNB, : Rajan Eye Care Hospital, Chennai.

[11]. Aasuri MK, Fernandes M, Pathan PP, Comparison of acrylic and polymethylmethacrylate lenses in a paediatric population, Indian J Ophthalmol, 2006 Jun:54(2):105-9.

[12]. Kuchle M, lausen B, Gusek-Schneider GC, Results and complications of hydrophobic acrylics Vs PMMA posterior chamber lenses in children under 17 years of age. Graefes Arch Clin Exp Ophthalmol:2003 Aug:241(8):637-41,Epub 2003 Jul17.

[13]. Mahmoud-Reza Panahi-Bazaz, MD; Mitra Zamani, MD; Bijan Abazar, MD: Hydrophilic Acrylic Versus PMMA intraocular Lens Implantation in Paediatric cataract Surgery : Journal of Ophthalmic and vision Research 2009; Vol 4, No 4. 